\title{
The Role of Multidetector Computed Tomography and the Forced Oscillation Technique in Assessing Lung Damage in Adults With Cystic Fibrosis
}

\author{
Letícia S Lacerda MSc, Agnaldo J Lopes PhD, Alysson R S Carvalho PhD, \\ Alan R M Guimarães MSc, Mônica C Firmida PhD, Marcos C S Castro MSc, \\ Roberto Mogami PhD, and Pedro L Melo PhD
}

\begin{abstract}
BACKGROUND: With increased survival rates and the consequent emergence of an adult population with cystic fibrosis (CF), developing novel tools for periodic evaluations of these patients has become a new challenge. Thus, we sought to determine the contribution of lung-volume quantification using multidetector computed tomography $(\mathrm{CT})$ in adults with $\mathrm{CF}$ and to investigate the association between structural changes and functional abnormalities. METHODS: This was a cross-sectional study in which 21 adults with $C F$ and 22 control subjects underwent lung-volume quantification using multidetector CT. Voxel densities were divided into 4 bands: $-1,000$ to -900 Hounsfield units (HU) (hyperaerated region), -900 to $-500 \mathrm{HU}$ (normally aerated region), -500 to $-100 \mathrm{HU}$ (poorly aerated region), and -100 to $100 \mathrm{HU}$ (non-aerated region). In addition, all participants performed pulmonary function tests including spirometry, body plethysmography, diffusion capacity for carbon monoxide, and the forced oscillation technique. RESULTS: Adults with CF had more non-aerated regions and poorly aerated regions with lung-volume quantification using multidetector CT than controls. Despite these abnormalities, total lung volume measured by lung-volume quantification using multidetector CT did not differ between subjects and controls. Total lung capacity (TLC) measured by body plethysmography correlated with both total lung volume $\left(r_{\mathrm{s}}=0.71, P<.001\right)$ and total air volume $\left(r_{\mathrm{s}}=0.71, P<.001\right)$ as measured with lungvolume quantification using multidetector $\mathrm{CT}$. While the hyperaerated regions correlated with the functional markers of gas retention in the lungs (increased residual volume (RV) and RV/TLC ratio), the poorly aerated regions correlated with the resistive parameters measured by the forced oscillation technique (increased intercept resistance and mean resistance). We also observed a correlation between normally aerated regions and highest pulmonary diffusion values $\left(r_{\mathrm{s}}=0.68, P<.001\right)$. CONCLUSIONS: In adults with CF, lung-volume quantification using multidetector CT can destimate the lung volumes of compartments with different densities and determine the aerated and non-aerated contents of the lungs; furthermore, lung-volume quantification using multidetector CT is clearly related to pulmonary function parameters. Key words: cystic fibrosis; diagnostic imaging; respiratory function tests; forced oscillation technique. [Respir Care 2018;63(4):430-440. ( 2018 Daedalus Enterprises]
\end{abstract}

\section{Introduction}

Cystic fibrosis (CF) is an autosomal, recessive, multisystem, progressive hereditary disease caused by a muta-

Ms Lacerda and Dr Melo are affiliated with the Postgraduate Program in Clinical and Experimental Physiopathology (FISCLINEX), School of Medical Sciences, State University of Rio de Janeiro, Rio de Janeiro, tion in the gene responsible for the coding of the CF transmembrane regulator protein. ${ }^{1}$ The disease affects 70,000 to 100,000 people worldwide, and its incidence varies among different regions of the world. ${ }^{2}$ More than $50 \%$ of

Brazil. Drs Lopes and Firmida and Mr Castro are affiliated with the Cystic Fibrosis Centre, Piquet Carneiro Polyclinic, State University of Rio de Janeiro, Rio de Janeiro, Brazil. Dr Lopes is affiliated with the 
the population with $\mathrm{CF}$ is $\geq 18$ years old, and there has been a significant increase in median survival from 27 years of age in 1986 to 40 years of age in 2013.1,2

Pulmonary involvement is the most influential factor on the morbidity and mortality of CF patients, accounting for $90 \%$ of deaths. ${ }^{3}$ Thickening of bronchial secretions occurs in the respiratory system, which leads to progressive airway obstruction and involvement of local defense mechanisms that combat chronic infections. Moreover, mucoid impactions and chronic inflammation of the bronchial walls cause bronchiectasis and destruction of the lung parenchyma. ${ }^{1,2}$ Sequential pulmonary function tests (PFTs), most commonly using spirometry, are routinely performed during the follow-up of CF patients to determine disease progression and therapeutic responses. Although more traditional PFTs are commonly used in the assessment of patients with $\mathrm{CF}$, the functional changes shown by these tests can be preceded by structural changes detected on computed tomography (CT) scans. ${ }^{4}$ Indeed, some studies have shown that spirometry is a suboptimal tool for monitoring earlystage CF lung disease and even later-stage CF characterized by clinically important respiratory involvement, which indicates the need to develop new PFTs for functional evaluation. ${ }^{5,6}$

In this context, the forced oscillation technique, a noninvasive and easy-to-perform method, has shown great potential for evaluating pulmonary involvement in CF by assessing both resistive and reactive properties of the respiratory system. ${ }^{7}$ Recent studies by our research group successfully applied this method in the early diagnosis of respiratory abnormalities in workers exposed to asbestos ${ }^{8}$ and in smokers, ${ }^{9}$ as well as in the investigation of patho-

Rehabilitation Sciences Post-Graduation Program, Augusto Motta University Center, Rio de Janeiro, Brazil. Drs Lopes, Mogami, and Melo are affiliated with the Postgraduate Programme in Medical Sciences, School of Medical Sciences, State University of Rio de Janeiro, Rio de Janeiro, Brazil. Dr Carvalho is affiliated with the Laboratory of Respiration Physiology, Carlos Chagas Filho Institute of Biophysics, Federal University of Rio de Janeiro, Rio de Janeiro, Brazil. Dr Carvalho and Mr Guimarães are affiliated with the Laboratory of Pulmonary Engineering, Biomedical Engineering Program, Alberto Luiz Coimbra Institute of Post-Graduation and Research in Engineering, Federal University of Rio de Janeiro, Rio de Janeiro, Brazil. Dr Mogami is affiliated with the Department of Radiology, State University of Rio de Janeiro, Rio de Janeiro, Brazil. Dr Melo is affiliated with the Biomedical Instrumentation Laboratory, Institute of Biology Roberto Alcantara Gomes and Laboratory of Clinical and Experimental Research in Vascular Biology (BioVasc), State University of Rio de Janeiro, Rio de Janeiro, Brazil.

The authors have disclosed no conflicts of interest.

Correspondence: Agnaldo J Lopes PhD, Rua Araguaia, 1266, bloco 1/405, Freguesia, Jacarepaguá, 22745-271, Rio de Janeiro, Brasil. E-mail: agnaldolopes.uerj@gmail.com.

DOI: $10.4187 /$ respcare. 05815

\section{QUICK LOOK}

\section{Current knowledge}

There is still no widely accepted standard imaging test to evaluate lung disease in adults with cystic fibrosis (CF). The quantification of lung volume using multidetector computed tomography (CT) was recently introduced to measure lung density. Moreover, the forced oscillation technique has shown great potential for analysis of pulmonary involvement in patients with $\mathrm{CF}$.

\section{What this paper contributes to our knowledge}

Adults with CF presented greater non-aerated and poorly aerated regions in relation to the volume of the lungs, as evaluated by quantification of lung volume using multidetector CT. When evaluated via the forced oscillation technique, CF subjects showed changes in both resistive and reactive properties of the respiratory system. The total lung volume assessed by quantification of lung volume using multidetector CT was positively and strongly correlated with the thoracic gas volume measured by body plethysmography. Moreover, findings from quantification of lung volume using multidetector CT were significantly associated with the indices provided by spirometry, diffusion capacity for carbon monoxide, and the forced oscillation technique.

physiological changes in subjects with sarcoidosis, ${ }^{10}$ silicosis, ${ }^{11}$ and COPD. ${ }^{12}$ Similar clinical studies have also been performed by other researchers who have investigated the detection of initial obstructive airway disease in subjects with asthma, ${ }^{13}$ changes in lung mechanics after bariatric surgery, ${ }^{14}$ airway obstruction in sleep apnea, ${ }^{15}$ and primary Sjögren's syndrome. ${ }^{16}$

Numerous studies have demonstrated the superiority of CT over chest radiography for the morphological evaluation of lung diseases, notably for the diagnosis and follow-up of chronic lung diseases such as CF. ${ }^{17,18}$ Despite this great advantage of CT, there is still no widely accepted standard imaging test to evaluate lung disease in adults with CF. ${ }^{19}$ Lung-volume quantification using multidetector CT was recently introduced with the aim of measuring lung density based on histogram analysis of the frequency distribution of lung attenuation values in Hounsfield units (HU). ${ }^{20-23}$ The analysis of voxel density distribution represents an important tool for studying the aeration distribution in CT slices. Thus, lung-volume quantification using multidetector $\mathrm{CT}$ has great potential to expand existing knowledge of the pathophysiology of $\mathrm{CF}$ in adults, to increase the diagnostic yield, and to aid in the staging of pulmonary involvement. 


\section{Assessing Lung Damage in Adults With CF}

Due to the lifespan in CF has been increasing for several decades now emergence of an adult population with $\mathrm{CF}$ and the absence of studies evaluating the potential of lungvolume quantification using multidetector $\mathrm{CT}$ in conjunction with the forced oscillation technique in this group of subjects, evaluating the contribution of these techniques to $\mathrm{CF}$ is of particular interest. Thus, the objectives of our study were to determine the type and extent of lung-volume quantification using multidetector $\mathrm{CT}$ findings in adults with $\mathrm{CF}$ and to investigate the association between structural lesions assessed with lung-volume quantification using multidetector $\mathrm{CT}$ and lung function parameters, especially those measured by the forced oscillation technique.

\section{Methods}

\section{Subjects}

We conducted this cross-sectional study between May 2016 and January 2017, with a convenience sample of 26 $\mathrm{CF}$ subjects recruited at the Piquet Carneiro Polyclinic at the State University of Rio de Janeiro, Brazil. Disease diagnosis was based on the presence of at least 2 of the following criteria: sweat chloride concentration $>60 \mathrm{mmol} / \mathrm{L}, 2$ clinical features consistent with $\mathrm{CF}$, or genetic testing demonstrating 2 mutations associated with CF. ${ }^{24}$ Patients of both genders age $\geq 18$ y were included in the study. The following exclusion criteria were used: clinical instability (evidence of an exacerbation or receiving medical treatment for an exacerbation in the 2 weeks prior to admission to the clinic), ${ }^{25}$ history of previous or current smoking, report of previous pleuropulmonary disease not related to $\mathrm{CF}$, and inability to perform PFTs or chest CT. An exacerbation was defined as the presence of any 4 of the following manifestations: increased cough, increased sputum production, increased dyspnea, new or increased hemoptysis, fatigue, oral temperature $>38^{\circ} \mathrm{C}$, sinus pain, decreased $\mathrm{FEV}_{1}$ by $\geq 10 \%$ from a previously recorded value, and radiographic changes indicative of infection. ${ }^{25,26}$

Through medical records and CT scans stored at our institution, we also included a control group of healthy volunteers who previously underwent chest $\mathrm{CT}$ for other reasons. Inclusion criteria for the control group were inspiratory/expiratory CT scans without any abnormalities and no history of smoking or chronic lung disease. Individuals in the control group were invited to perform the PFTs. In case of any abnormalities in PFTs (ie, any value below the lower limit of normal or above the upper limit of normal in relation to the predicted value), the subject was excluded from the study. This control group was paired in age and gender with the $\mathrm{CF}$ group.

The project was approved by the Research Ethics Committee of our institution under the number
CAAE-27352814.8.0000.5259 and complied with the provisions of the Declaration of Helsinki. All individuals signed a consent form. The project received financial support from the Brazilian Council for Scientific and Technological Development and the Rio de Janeiro State Research Supporting Foundation.

\section{Pulmonary Function Testing}

The PFTs performed were spirometry, body plethysmography, and diffusing capacity of the lung for carbon monoxide $\left(\mathrm{D}_{\mathrm{LCO}}\right)$. The exams were performed using an HDpft 3000 system (nSpire Health, Longmont, Colorado) according to the standards outlined by the American Thoracic Society/European Respiratory Society. ${ }^{27}$ The equations used for predicted values were reported by Pereira et $\mathrm{al}^{28}$ for spirometry, Neder et $\mathrm{al}^{29}$ for body plethysmography, and Neder et $\mathrm{al}^{30}$ for $\mathrm{D}_{\mathrm{LCO}}$ measurements, and the results were expressed as a percentage of the predicted values. In addition, we also performed the forced oscillation technique using a device developed at the Biomedical Instrumentation Laboratory, which was used previously in several clinical studies. ${ }^{8,10-12,31,32}$ The standardization of this method has been previously reported. ${ }^{33}$ To avoid the effects of the deep inhalation maneuver on the airways, patients were initially evaluated by the forced oscillation technique upon inclusion in the study. Spirometry, body plethysmography, and $\mathrm{D}_{\mathrm{LCO}}$ measurements were then sequentially performed.

\section{CT Scan Protocol}

CT scans were performed using a 64-channel Multislice Philips system (Brilliance 40, Philips Medical Systems, Cleveland, Ohio) capable of performing volumetric acquisitions with subsequent multiplanar reconstructions. Acquisition was always performed in the axial plane, with subjects in dorsal decubitus, using the following technical parameters: $120 \mathrm{kV}, 458 \mathrm{~mA}$ (which varied according to the biotype of the subject), slice thickness of $2 \mathrm{~mm}$, and pitch of $2 \mathrm{~mm}$ from the jugular notch to the xiphoid process during maximal inspiration and expiration. There was no inclination of the gantry. After image acquisition, a high-resolution reconstruction with a $512 \times 512$ matrix was performed using a high-frequency algorithm, a window width of 1,200 $\mathrm{HU}$, and a mean center level of -800 HU. The CT scans were interpreted independently by 2 experienced radiologists, who were blinded to the clinical and functional data of the subjects evaluated; in addition, the CT scans of the control and CF groups were mixed for evaluation of the images. Disagreements were resolved by consensus. 


\section{Image Processing}

The first step of density and volumetry was the segmentation of the pulmonary parenchyma, which was performed using the OsiriX program (OsiriX 64-bits, Pixmeo Sarl, Geneva, Switzerland). This process consisted of the selection of the lung parenchyma and specific altered regions, such as areas of hyperinflation, excluding the chest wall, heart, and large vessels. After segmentation and export of the lung parenchyma images, the images were processed according to the instructions of the DICOMDir file in a CT-processing program written in MATLAB 2014a (MathWorks, Natick, Massachusetts) at the Laboratory of Pulmonary Engineering, Biomedical Engineering Program, Alberto Luiz Coimbra Institute of Post-Graduation and Research in Engineering, Federal University of Rio de Janeiro, Rio de Janeiro, Brazil.

Analysis of the voxel density distribution is an important tool in studying the aeration distribution in a CT slice. The distribution histogram of the voxels was divided into compartments, which varied between $-1,000$ and +100 HU. The voxel densities were divided into 4 bands within the following ranges: $-1,000$ to $-900 \mathrm{HU}$ (hyperaerated region), -900 to $-500 \mathrm{HU}$ (normally aerated region), -500 to $-100 \mathrm{HU}$ (poorly aerated region), and -100 to $100 \mathrm{HU}$ (non-aerated region). These values were determined according to previously proposed classifications. ${ }^{11,21,34,35}$ The total lung volume and the total air volume were calculated considering only the image contained within the region of interest. The total lung volume (ie, the sum of air plus tissue volume) was calculated as (size of the pixel $)^{2} \times$ slice thickness $\times$ total number of pixels of the region of interest for the whole lung. ${ }^{21,34,35}$

\section{Statistical Analysis}

The sample size for this study was calculated using MedCalc 8.2 software (Medicalc Software, Mariakerke, Belgium). A minimum sample size of 21 cases was required to test the alternative hypothesis that the correlation coefficient (ie, correlation between the structural lesion assessed with lung-volume quantification using multidetector $\mathrm{CT}$ and the forced oscillation technique parameter) was $>0.40$ (or $<-0.40)$, assuming a type- 1 error of $5 \%$ and a type- 2 error of $20 \% .{ }^{36}$

Non-parametric tests were applied because almost none of the variables presented a Gaussian distribution, as the normality hypothesis was rejected according to the Shapiro-Wilk test. Comparisons of the clinical variables, PFTs, and findings from the lung-volume quantification using multidetector CT between the experimental and control groups were evaluated using the Mann-Whitney test for numerical data and the chi-square test for categorical data. To evaluate the associations between the numerical vari- ables of PFTs and lung-volume quantification using multidetector CT, the Spearman correlation coefficient $\left(r_{s}\right)$ was used. Multivariate forward stepwise regression analysis was performed to determine the dependent relationship of lung function parameters on lung-volume quantification using multidetector CT variables. Natural logarithmic transformation was applied to the variables dependent on lungvolume quantification using multidetector $\mathrm{CT}$. The clinical potential of the lung-volume quantification using multidetector CT indices for the detection of pulmonary alterations in subjects with $\mathrm{CF}$ was evaluated by means of receiver operating characteristic curves. The criterion for determining significance was $P=.05$. Statistical analysis was performed using SAS 6.11 software (SAS Institute, Cary, North Carolina).

\section{Results}

Among the 26 patients who were evaluated for inclusion in the study, 5 were excluded ( 3 due to difficulty performing spirometry, and 2 due to clinical instability during the study). Thus, the CF group $(n=21)$ consisted of 14 females and 7 males, with a median age of $24 \mathrm{y}$ (interquartile range 19.5-29 y), and $>60 \%$ of included subjects were chronically colonized by Pseudomonas aeruginosa. The control group $(n=22)$ consisted of 15 females and 7 males, with a median age of 30.5 y (interquartile range $26-35.3 \mathrm{y}$ ). In the forced oscillation technique exam, the adults with $\mathrm{CF}$ presented higher values of intercept resistance, mean resistance, resonance frequency, and impedance module at $4 \mathrm{~Hz}$, and lower values of mean reactance and dynamic compliance of the respiratory system compared with controls. Comparisons of clinical and pulmonary function data between the adult subjects with $\mathrm{CF}$ and the control subjects are shown in Table 1.

In CT scans, all adults with CF showed signs characteristic of lung disease in at least 1 lobe. The alterations found in CT scans included air trapping and mosaic attenuation $(81 \%)$; bronchiectasis, thickening of the bronchial walls, and mucous plugs $(76.2 \%)$; consolidations/collapse (61.9\%); sacculations/abscess (47.6\%); ground glass opacities (38.1\%); septal thickening $(33.3 \%)$; and bubbles/emphysema (19\%). With both inspiratory and expiratory lung-volume quantification using multidetector $\mathrm{CT}, \mathrm{CF}$ subjects presented greater nonaerated area based on either the absolute number of non-aerated regions or total percentage of the non-aerated area. Inspiratory lung-volume quantification using multidetector CT also demonstrated that CF subjects presented greater poorly aerated area based on either the absolute number of non-aerated regions or total percentage of the non-aerated area. Comparisons of inspiratory and expiratory lung-volume quantification using multi- 


\section{Assessing Lung Damage in Adults With CF}

Table 1. General Characteristics and Pulmonary Function Parameters of Patients With Cystic Fibrosis and Control Group

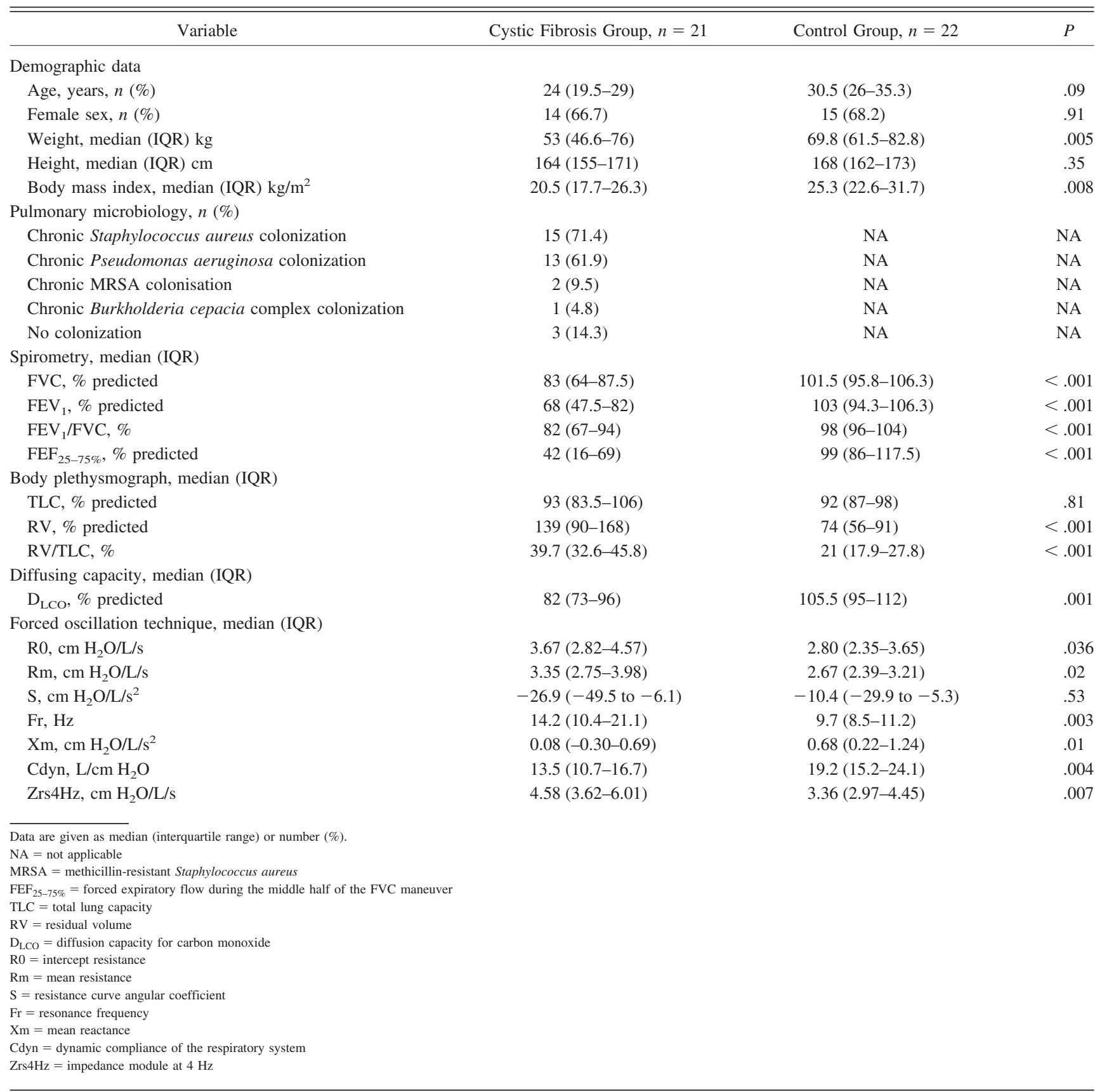

detector CT data between the CF subjects and the control subjects are shown in Table 2.

We next evaluated the correlations between the findings from lung-volume quantification using multidetector CT and the PFT parameters (Tables 3 and 4). For inspiratory lung-volume quantification using multidetector CT, strong correlations were observed between total lung volume and total lung capacity (TLC) $\left(\mathrm{r}_{\mathrm{s}}=0.71, P<.001\right)$, between total air volume and TLC $\left(\mathrm{r}_{\mathrm{s}}=0.71, P<.001\right)$, between total lung volume and $\mathrm{D}_{\mathrm{LCO}}\left(\mathrm{r}_{\mathrm{s}}=0.69, P<.001\right)$, and between total air volume and $\mathrm{D}_{\mathrm{LCO}}\left(\mathrm{r}_{\mathrm{s}}=0.69, P<.001\right)$. The poorly aerated region was significantly correlated with residual volume $\left(\mathrm{RV} ; \mathrm{r}_{\mathrm{s}}=0.42, P=.005\right), \mathrm{RV} / \mathrm{TLC}$ $\left(\mathrm{r}_{\mathrm{s}}=0.35, P=.02\right)$, and forced expiratory flow during the middle half of the FVC $\left(\mathrm{FEF}_{27-75 \%}\right)\left(\mathrm{r}_{\mathrm{s}}=-0.45, P=.003\right)$. For expiratory lung-volume quantification using multidetector CT, the poorly aerated region was significantly correlated with the following forced oscillation technique parameters: intercept resistance $\left(\mathrm{r}_{\mathrm{s}}=-0.41, P=.02\right)$ and mean resistance $\left(\mathrm{r}_{\mathrm{s}}=-0.44, P=.02\right)$. The hyperaerated 


\section{Assessing Lung Damage in Adults With CF}

Table 2. Variables of Inspiratory and Expiratory Computed Tomography According to the Group

\begin{tabular}{|c|c|c|c|c|c|c|}
\hline \multirow[b]{2}{*}{ Variable } & \multicolumn{3}{|c|}{ Inspiratory Computed Tomography } & \multicolumn{3}{|c|}{ Expiratory Computed Tomography } \\
\hline & $\begin{array}{c}\text { Cystic Fibrosis Group, } \\
n=21\end{array}$ & $\begin{array}{c}\text { Control Group, } \\
\quad n=22\end{array}$ & $P$ & $\begin{array}{c}\text { Cystic Fibrosis Group, } \\
n=21\end{array}$ & $\begin{array}{c}\text { Control Group, } \\
n=22\end{array}$ & $P$ \\
\hline $\mathrm{TLV}, \mathrm{mL}$ & $4112(3389-5144)$ & $4242(3669-5338)$ & .45 & $2961(2150-3472)$ & $2182(1528-3044)$ & .11 \\
\hline $\mathrm{TAV}, \mathrm{mL}$ & $3469(2693-4264)$ & $3622(3055-4453)$ & .44 & $1997(1543-2485)$ & $1446(940-2314)$ & .16 \\
\hline Non, mL & $34.7(12.7-97.4)$ & $13.8(9.5-19.8)$ & .02 & $39.6(27.4-114)$ & $11.5(8.5-25)$ & .001 \\
\hline Non, \% TLV & $0.88(0.29-1.69)$ & $0.31(0.22-0.52)$ & .008 & $1.94(1.14-3.47)$ & $0.63(0.38-1.21)$ & .002 \\
\hline Poor, mL & $139(102-258)$ & $89.9(73-116)$ & .002 & $230(171-330)$ & $279(112-297)$ & .63 \\
\hline Poor, \% TLV & $3.42(2.61-5.25)$ & $2.11(1.53-2.66)$ & .001 & $8.15(6.25-11.9)$ & $12.8(3.79-18)$ & .38 \\
\hline Norm, mL & $2920(2542-3306)$ & $3156(2797-3554)$ & .30 & $2362(1879-2890)$ & $1858(1218-2616)$ & .18 \\
\hline Norm, \% TLV & $71.6(61.6-79.7)$ & $74.2(67.3-79.8)$ & .58 & $83.4(77.1-86)$ & $83.9(80.3-85.2)$ & .87 \\
\hline Hyper, mL & $966(652-1519)$ & $1027(556-1396)$ & .94 & $158(55-267)$ & $34(14-302)$ & .19 \\
\hline Hyper, \% TLV & $22.8(15.4-35.6)$ & $23(15.8-31)$ & .94 & $5.03(2.35-8.44)$ & $1.58(0.98-9.98)$ & .29 \\
\hline $\begin{array}{l}\text { Data are given as me } \\
\text { TLV }=\text { total lung vol } \\
\text { TAV = total air volu } \\
\text { Non = non-aerated re } \\
\text { Poor = poorly aeratec } \\
\text { Norm = normally aer } \\
\text { Hyper = hyperaerated }\end{array}$ & terquartile range). & & & & & \\
\hline
\end{tabular}

Table 3. Spearman's Correlation Coefficients Between the Inspiratory Lung-Volume Quantification by Multidetector Computed Tomography Values and the Pulmonary Function Parameters

\begin{tabular}{|c|c|c|c|c|c|c|c|c|c|}
\hline Variable & FVC, L & $\mathrm{FEV}_{1} / \mathrm{FVC}, \%$ & $\begin{array}{c}\mathrm{FEF}_{25-75 \%}, \\
\mathrm{~L} / \mathrm{s}\end{array}$ & TLC, L & $\mathrm{RV}, \mathrm{L}$ & RV/TLC, \% & $\begin{array}{c}\mathrm{D}_{\mathrm{LCO}}, \\
\mathrm{mL} / \mathrm{min} / \mathrm{mm} \mathrm{Hg}\end{array}$ & $\begin{array}{l}\mathrm{R} 0, \mathrm{~cm} \\
\mathrm{H}_{2} \mathrm{O} / \mathrm{L} / \mathrm{s}\end{array}$ & $\begin{array}{l}\mathrm{Rm}, \mathrm{cm} \\
\mathrm{H}_{2} \mathrm{O} / \mathrm{L} / \mathrm{s}\end{array}$ \\
\hline $\mathrm{TLV}, \mathrm{mL}$ & $0.61 *$ & -0.09 & 0.10 & $0.71 *$ & 0.22 & -0.13 & $0.69 *$ & -0.24 & -0.25 \\
\hline TAV, mL & $0.62 *$ & -0.07 & 0.13 & $0.71 *$ & 0.20 & -0.14 & $0.69 *$ & -0.21 & -0.21 \\
\hline Non, mL & -0.01 & -0.11 & -0.24 & 0.14 & 0.24 & 0.02 & 0.17 & -0.07 & -0.07 \\
\hline Non, \% TLV & -0.17 & -0.10 & -0.30 & -0.02 & 0.22 & 0.22 & 0.02 & -0.03 & -0.02 \\
\hline Poor, mL & -0.16 & -0.31 & -0.45 & 0.11 & 0.42 & 0.35 & -0.02 & -0.01 & 0.01 \\
\hline Poor, \% TLV & -0.39 & -0.20 & -0.45 & -0.20 & 0.28 & 0.37 & -0.27 & 0.02 & 0.04 \\
\hline Norm, mL & $0.57 *$ & -0.03 & 0.18 & $0.62 *$ & 0.05 & -0.26 & 0.68* & -0.43 & -0.46 \\
\hline Norm, \% TLV & -0.20 & 0.17 & 0.14 & -0.28 & -0.29 & -0.17 & -0.14 & -0.17 & -0.16 \\
\hline Hyper, mL & 0.40 & -0.15 & -0.02 & $0.51 *$ & 0.31 & 0.10 & $0.36 *$ & 0.10 & 0.06 \\
\hline Hyper, \% TLV & 0.27 & -0.13 & -0.05 & 0.30 & 0.22 & 0.10 & 0.17 & 0.17 & 0.16 \\
\hline $\begin{array}{l}\text { The values in bold re } \\
\mathrm{TLV}=\text { total lung vol } \\
\mathrm{TAV}=\text { total air volu } \\
\text { Non = non-aerated re } \\
\text { Poor = poorly aerate } \\
\text { Norm = normally aer } \\
\text { Hyper = hyperaerate } \\
\mathrm{FEF}_{25-75 \%}=\text { forced } \\
\mathrm{TLC} \text { total lung cap } \\
\mathrm{RV}=\text { residual volum } \\
\mathrm{D}_{\mathrm{LCO}}=\text { diffusion cap } \\
\mathrm{R} 0=\text { intercept resist } \\
\mathrm{Rm}=\text { mean resistanc }\end{array}$ & $\begin{array}{l}\text { o significant } \\
\text { region } \\
\text { region } \\
\text { atory flow d } \\
\text { for carbon }\end{array}$ & $g$ the middle half of $t$ & $\mathrm{VC}$ maneuver & & & & & & \\
\hline
\end{tabular}

region was significantly correlated with $\mathrm{RV}\left(\mathrm{r}_{\mathrm{s}}=0.59\right.$, $P<.001), \mathrm{RV} / \mathrm{TLC}\left(\mathrm{r}_{\mathrm{s}}=0.45, P=.02\right)$, and $\mathrm{FEF}_{27-75 \%}$ $\left(\mathrm{r}_{\mathrm{s}}=-0.49, P=.007\right)$.

We also constructed models to explain the dependent relationship between lung-volume quantification using multidetector CT variables and lung function parameters.
The models with the greatest clinical relevance and statistical significance are shown in Table 5. We also found that poorly aerated regions more accurately detected the initial lung disease in $\mathrm{CF}$ than non-aerated regions. The receiver operating characteristic curves, areas under the curves, and 95\% CIs for the most accurate parameters observed in 


\section{Assessing Lung Damage in Adults With CF}

Table 4. Spearman's Correlation Coefficients Between Expiratory Lung-Volume Quantification by Multidetector Computed Tomography Values and the Pulmonary Function Parameters

\begin{tabular}{|c|c|c|c|c|c|c|c|c|c|}
\hline Variable & FVC, L & $\mathrm{FEV}_{1} / \mathrm{FVC}, \%$ & $\begin{array}{c}\mathrm{FEF}_{25-75 \%}, \\
\mathrm{~L} / \mathrm{s}\end{array}$ & TLC, L & $\mathrm{RV}, \mathrm{L}$ & RV/TLC, \% & $\begin{array}{c}\mathrm{D}_{\mathrm{LCO}}, \\
\mathrm{mL} / \mathrm{min} / \mathrm{mm} \mathrm{Hg}\end{array}$ & $\begin{array}{c}\mathrm{R} 0, \mathrm{~cm} \\
\mathrm{H}_{2} \mathrm{O} / \mathrm{L} / \mathrm{s}\end{array}$ & $\begin{array}{l}\mathrm{Rm}, \mathrm{cm} \\
\mathrm{H}_{2} \mathrm{O} / \mathrm{L} / \mathrm{s}\end{array}$ \\
\hline $\mathrm{TLV}, \mathrm{mL}$ & 0.13 & -0.26 & 0.39 & 0.45 & 0.56 & 0.34 & 0.38 & 0.05 & 0.05 \\
\hline $\mathrm{TAV}, \mathrm{mL}$ & 0.13 & -0.26 & 0.39 & 0.44 & 0.57 & 0.36 & 0.34 & 0.07 & 0.08 \\
\hline Non, mL & -0.17 & -0.22 & -0.47 & 0.07 & 0.39 & 0.33 & -0.01 & 0.04 & 0.04 \\
\hline Non, \% TLV & -0.24 & -0.14 & -0.40 & -0.08 & 0.27 & 0.27 & -0.15 & 0.07 & 0.07 \\
\hline Poor, mL & 0.23 & 0.01 & -0.01 & 0.15 & 0.01 & -0.14 & 0.18 & -0.41 & -0.44 \\
\hline Poor, \% TLV & 0.11 & 0.16 & 0.28 & -0.14 & -0.35 & -0.35 & -0.07 & -0.44 & -0.47 \\
\hline Norm, mL & 0.19 & -0.17 & -0.27 & 0.44 & 0.47 & 0.24 & 0.44 & -0.01 & -0.01 \\
\hline Norm, \% TLV & 0.01 & 0.11 & 0.21 & 0.03 & -0.05 & -0.06 & 0.14 & 0.21 & 0.22 \\
\hline Hyper, mL & -0.01 & -0.35 & -0.49 & 0.35 & $0.59 *$ & 0.45 & 0.14 & 0.23 & 0.24 \\
\hline Hyper, \% TLV & -0.07 & -0.36 & -0.50 & 0.31 & 0.57 & 0.47 & 0.06 & 0.30 & 0.30 \\
\hline $\begin{array}{l}\text { The values in bold re } \\
\mathrm{TLV}=\text { total lung vol } \\
\mathrm{TAV}=\text { total air volu } \\
\text { Non }=\text { non-aerated re } \\
\text { Poor = poorly aeratec } \\
\text { Norm = normally aer } \\
\text { Hyper }=\text { hyperaeratec } \mathrm{FEF}_{25-75 \%}=\text { forced } \\
\mathrm{TLC}=\text { total lung cap } \\
\mathrm{RV}=\text { residual volum } \\
\mathrm{D}_{\mathrm{LCO}}=\text { diffusion cap } \\
\mathrm{R} 0=\text { intercept resista } \\
\mathrm{Rm}=\text { mean resistanc }\end{array}$ & $\begin{array}{l}\text { gion } \\
\text { l region } \\
\text { gion } \\
\text { ratory flow d } \\
\text { y } \\
\text { y for carbon }\end{array}$ & $\begin{array}{l}\text { g the middle half of } t \\
\text { noxide }\end{array}$ & FVC maneuver & & & & & & \\
\hline
\end{tabular}

Table 5. Relationship Between the Variables for Lung-Volume Quantification by Multidetector Computed Tomography and the Lung Function Parameters

\begin{tabular}{|c|c|c|c|}
\hline Outcome Variable & Independent Variables & Regression Coefficient $(\beta), 95 \%$ CI & $P$ \\
\hline \multicolumn{4}{|l|}{ Inspiratory Q-MDCT } \\
\hline Poor, mL & $\mathrm{RV}, \mathrm{L}$ & $0.34(0.14-0.54)$ & .002 \\
\hline \multirow[t]{2}{*}{ Norm, mL } & $\mathrm{D}_{\mathrm{LCO}}, \mathrm{mL} / \mathrm{min} / \mathrm{mm} \mathrm{Hg}$ & $0.01(0.01-0.02)$ & .005 \\
\hline & TLC, L & $0.06(0.01-0.11)$ & .01 \\
\hline \multicolumn{4}{|l|}{ Expiratory Q-MDCT } \\
\hline Poor, $\mathrm{mL}$ & $\mathrm{Rm}, \mathrm{cm} \mathrm{H}_{2} \mathrm{O} / \mathrm{L} / \mathrm{s}$ & $-0.29(-0.48$ to -0.09$)$ & .005 \\
\hline \multirow[t]{3}{*}{ Norm, mL } & TLC, L & $0.27(0.14-0.39)$ & $<.001$ \\
\hline & FVC, L & $-0.37(-0.58$ to -0.16$)$ & .001 \\
\hline & $\mathrm{D}_{\mathrm{LCO}}, \mathrm{mL} / \mathrm{min} / \mathrm{mm} \mathrm{Hg}$ & $0.03(0.01-0.06)$ & .01 \\
\hline \multicolumn{4}{|c|}{$\overline{\text { Poor }=\text { poorly aerated region }}$} \\
\hline \multicolumn{4}{|c|}{ Norm $=$ normally aerated region } \\
\hline \multicolumn{4}{|c|}{$\mathrm{RV}=$ residual volume } \\
\hline \multicolumn{4}{|c|}{$\mathrm{D}_{\mathrm{LCO}}=$ diffusing capacity of the lung for carbon monoxide } \\
\hline \multicolumn{4}{|c|}{ TLC $=$ total lung capacity } \\
\hline \multicolumn{4}{|l|}{$\mathrm{Rm}=$ mean resistance } \\
\hline $\mathrm{FVC}=$ forced vital capacity & & & \\
\hline
\end{tabular}

inspiratory lung-volume quantification using multidetector CT are shown in Figure 1.

\section{Discussion}

The main findings of our study were that adults with $\mathrm{CF}$ presented larger non-aerated and poorly aerated regions in relation to the volume of the lungs evaluated with lung- volume quantification using multidetector $\mathrm{CT}$ than control subjects. When evaluated with the forced oscillation technique, CF subjects showed changes in both resistive properties (intercept resistance and mean resistance) and reactive properties (resonance frequency, mean reactance, and dynamic compliance) of the respiratory system. The total lung volume assessed with lung-volume quantification using multidetector CT was positively and strongly corre- 


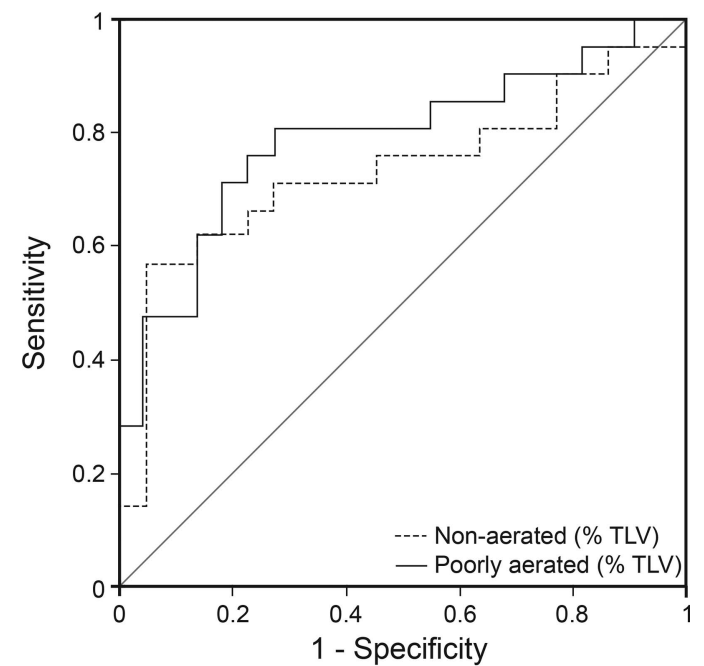

Fig. 1. Receiver operating characteristic curves, area under the curves (AUC), and $95 \% \mathrm{Cl}$ in inspiratory lung volume quantification using multidetector computed tomography for the non-aerated region (AUC $=0.74, P=.008,95 \% \mathrm{Cl} 0.58-0.89$ ) and the poorly aerated region $(A \cup C=0.79, P=.001,95 \% \mathrm{Cl} 0.65-0.93) . T L V=$ total lung volume.

lated with thoracic gas volume measured with body plethysmography. Moreover, findings with lung-volume quantification using multidetector $\mathrm{CT}$ were significantly associated with the indices provided by spirometry, $\mathrm{D}_{\mathrm{LCO}}$, and the forced oscillation technique.

Our findings show that in adults with CF, lung-volume quantification using multidetector $\mathrm{CT}$ was able to estimate compartment volumes with different densities and to determine the aerated and non-aerated contents of the lungs, providing information on the volume of the organ and its compartments. However, in line with the study by Wielpütz et al, ${ }^{22}$ the total lung volume of $\mathrm{CF}$ subjects remained unchanged for both inspiratory and expiratory lung-volume quantification using multidetector CT compared with the total lung volume of control subjects. This finding indicates that, despite the imbalance between the volume of non-aerated, poorly aerated, normally aerated, and hyperaerated regions, the total lung volume was close to values observed in healthy lungs, which is translated anatomopathologically by the presence of areas with increased density (mucoid impactions, consolidations, and collapses) in the lungs of adults with $\mathrm{CF}$, along with areas of diminished density (air trapping, bubbles, and emphysema). ${ }^{37,38}$ In addition, we observed that the adult $\mathrm{CF}$ subjects had larger non-aerated and poorly aerated regions with both inspiratory and expiratory lung-volume quantification using multidetector CT. These regions exhibited a higher density than the parenchyma with normal aeration, which suggests the presence of areas of consolidation, collapse, and fibrosis in CF. ${ }^{7-19}$ Considering clinical practice, lungvolume quantification using multidetector CT may con- tribute to the early identification of lung disease. In fact, we have found that the presence of poorly aerated regions on inspiratory lung-volume quantification using multidetector CT has good accuracy for diagnosing pulmonary disease in CF. This becomes even more relevant in light of the growing number of individuals being diagnosed with atypical forms and the increased life expectancy provided by new treatments (including CF transmembrane conductance regulator modulators). ${ }^{39}$

In this paper, we showed that total lung volume and total air volume assessed with inspiratory lung-volume quantification using multidetector $\mathrm{CT}$ were positively and strongly correlated with TLC as measured by body plethysmography. Although these parameters are acquired using different diagnostic methods, the physiological and conceptual similarities between the volumetric variables make it possible for both lung-volume quantification using multidetector CT and body plethysmography to be used as important tools in the follow-up of adults with CF. Increased patient survival in recent decades has emphasized the need for periodic evaluations of adults with CF; therefore, the relationships between lung function and imaging parameters further support the routine performance of PFTs in this population to reduce concern about the frequent use of ionizing radiation. It is worth noting that both overall lung-volume quantification using multidetector CT measurements (total lung volume and total air volume) and the total thoracic gas volume assessed by PFTs (TLC) did not differ significantly between the subjects and the controls, which reinforces our hypothesis that regions of higher density are counterbalanced by lower-density regions in adults with CF.

Some studies have shown that emphysema is a clinically relevant phenotype and contributes to the severity of lung disease in adults with CF. ${ }^{22,40,41}$ In our study, we observed significant correlations of hyperaerated regions (mainly in expiratory lung-volume quantification using multidetector CT exams) with increases in RV and RV/ TLC, which are functional markers of airway obstruction and gas retention in the lungs. ${ }^{23}$ Because lung voxels are attributed to emphysema at densities $\geq-950$ $\mathrm{HU}, 22,42$ the hyperaerated region defined in our study primarily corresponded to emphysematous lesions. This finding reinforces the idea that the presence and extent of emphysema in lung-volume quantification using multidetector CT may serve as a marker of the severity of lung dysfunction in adults with CF. 22

The forced oscillation technique allows respiratory mechanics to be evaluated in a complementary manner to traditional PFTs and has been increasingly incorporated in the functional evaluation of chronic respiratory diseases. ${ }^{43}$ Another important advantage is that the forced oscillation technique requires only passive cooperation and does not entail any forced expiratory maneuvers. In fact, 3 of the 
recruited patients had difficulty performing spirometry and were excluded from the study. In our investigation, adults with $\mathrm{CF}$ showed lower mean reactance values than controls. Because mean reactance reflects the inhomogeneity of the respiratory system, we believe that the irregular distribution of preferential involvement in the upper lobes and changes in the small airways may explain, at least in part, the decline of mean reactance in adults with $\mathrm{CF}^{7,44} \mathrm{In}$ addition, we observed higher impedance module at $4 \mathrm{~Hz}$ values in adults with $\mathrm{CF}$ than in controls. The impedance module at $4 \mathrm{~Hz}$ is related to the total mechanical load of the respiratory system, describing the effect resulting from respiratory system resistance, compliance, and inertia. ${ }^{45}$ This parameter expresses the final result of the interactions of all pathophysiological changes involved in the respiratory mechanics of subjects with $\mathrm{CF}$, including reduced airway caliber by mucoid impactions, decreased elastic properties with reduction in the dynamic compliance of the respiratory system, and inhomogeneity of the respiratory system.7,44

In inspiratory lung-volume quantification using multidetector CT, as expected, we observed negative correlations between the normally aerated regions and the forced oscillation technique resistive parameters (intercept resistance and mean resistance), which is in agreement with the notion that resistance is lower in well-ventilated areas. In expiratory lung-volume quantification using multidetector $\mathrm{CT}$, we observed negative correlations between the poorly aerated regions and the forced oscillation technique resistive parameters. This is not surprising, as the poorly aerated regions represent areas with fibrosis conglomerates that cause radial traction on the caliber of the airways due to greater elastic recoil, which allows greater opening of the airways to any lung volume, in turn causing supranormal flow and reduced resistive parameters. Similar to the forced oscillation technique variables, we found significant correlations between $\mathrm{FEF}_{27-75 \%}$ and variables in lung-volume quantification using multidetector CT (especially during the expiratory phase), which supports the idea that these parameters characterize the small airways. ${ }^{7}$ Notably, we found associations between lungvolume quantification using multidetector $\mathrm{CT}$ and $\mathrm{D}_{\mathrm{LCO}}$, with the highest values of pulmonary diffusion observed in the normally aerated regions during inspiratory lungvolume quantification using multidetector $\mathrm{CT}$. These associations can be justified by the fact that $\mathrm{D}_{\mathrm{LCO}}$ directly depends on the surface area available for gas exchange, according to Fick's law, which calculates the rate of gas diffusion through the alveolar-capillary membrane. In fact, in adults with $\mathrm{CF}, \mathrm{D}_{\mathrm{LCO}}$ has been considered as one of the parameters that best portrays lung involvement in CT scans. ${ }^{46}$

Our study included some limitations, as can be found in any study. First, we evaluated a relatively small number of adults with CF; however, it is worth emphasizing that, in addition to the fact that $\mathrm{CF}$ is a rare condition, an adult population with CF has only emerged in recent decades in light of increased survival rates due to improvements in the therapeutic arsenal and respiratory physiotherapy. ${ }^{1} \mathrm{Sec}-$ ond, the patient and control groups were not statistically paired for body mass index because weight matching was hampered by the fact that CF commonly causes a state of malnutrition due to pancreatic impairment and malabsorption syndrome ${ }^{47}$; however, weight does not influence the parameters of the PFTs because it is not a factor in the reference equations that model pulmonary function. ${ }^{12} \mathrm{Fi}-$ nally, quantitative analysis of the airways through lungvolume quantification using multidetector $\mathrm{CT}$ could have been important in the correlation studies, especially in relation to the parameters provided by the forced oscillation technique. ${ }^{23,37}$ Despite these limitations, we believe that both lung-volume quantification using multidetector $\mathrm{CT}$ and the forced oscillation technique can help in the early diagnosis and more aggressive management of lung disease in CF. Thus, future studies can be dedicated to evaluating the longitudinal impact of these new tools in the management of $\mathrm{CF}$ patients.

\section{Conclusion}

Our study shows that there were larger non-aerated and poorly aerated regions in adults with CF. Despite these abnormalities, total lung volume measured with lung-volume quantification using multidetector $\mathrm{CT}$ remained unchanged and was associated with the total thoracic gas volume measured by body plethysmography. In these subjects, the hyperaerated regions were associated with the functional markers of gas retention in the lungs. Furthermore, the decrease in normally aerated regions was associated with increase of the resistive parameters revealed by the forced oscillation technique and reduced pulmonary diffusion. Taken together, lung-volume quantification using multidetector $\mathrm{CT}$ is able to estimate the lung volumes of compartments with different densities in adults with CF, in addition to being clearly associated with pulmonary function abnormalities.

\section{REFERENCES}

1. Leitch AE, Rodgers HC. Cystic fibrosis. J R Coll Physicians Edinb 2013;43(2):144-150.

2. Kelly J. Environmental scan of cystic fibrosis research worldwide. J Cyst Fibros 2017;16(3):367-370.

3. Belkin RA, Henig NR, Singer LG, Chaparro C, Rubenstein RC, Xie SX, et al. Risk factors for death of patients with cystic fibrosis awaiting lung transplantation. Am J Respir Crit Care Med 2006; 173(6):659-666.

4. de Jong PA, Lindblad A, Rubin L, Hop WC, de Jongste JC, Brink M, et al. Progression of lung disease on computed tomography and 


\section{Assessing Lung Damage in Adults With CF}

pulmonary function tests in children and adults with cystic fibrosis. Thorax 2006;61(1):80-85.

5. Sanders DB, Li Z, Rock MJ, Brody AS, Farrell PM. The sensitivity of lung disease surrogates in detecting chest $\mathrm{CT}$ abnormalities in children with cystic fibrosis. Pediatr Pulmonol 2012;47(6):567-573.

6. de Jong PA, Nakano Y, Lequin MH, Mayo JR, Woods R, Paré PD, et al. Progressive damage on high resolution computed tomography despite stable lung function in cystic fibrosis. Eur Respir J 2004; 23(1):93-97.

7. Lima AN, Faria AC, Lopes AJ, Jansen JM, Melo PL. Forced oscillations and respiratory system modeling in adults with cystic fibrosis. Biomed Eng Online 2015;14:11.

8. de Sa PM, Castro HA, Lopes AJ, Melo PL. Early diagnosis of respiratory abnormalities in asbestos-exposed workers by the forced oscillation technique. PLoS One 2016;11(9):e0161981.

9. Faria AC, Lopes AJ, Jansen JM, Melo PL. Evaluating the forced oscillation technique in the detection of early smoking-induced respiratory changes. Biomed Eng Online 2009;8:22.

10. Faria AC, Lopes AJ, Jansen JM, Melo PL. Assessment of respiratory mechanics in patients with sarcoidosis using forced oscillation: correlations with spirometric and volumetric measurements and diagnostic accuracy. Respiration 2009;78(1):93-104.

11. Lopes AJ, Mogami R, Camilo GB, Machado DC, Melo PL, Carvalho AR. Relationships between the pulmonary densitometry values obtained by $\mathrm{CT}$ and the forced oscillation technique parameters in patients with silicosis. Br J Radiol 2015;88(1049):20150028.

12. da Costa GM, Faria AC, Di Mango AM, Lopes AJ, Lopes de Melo P. Respiratory impedance and response to salbutamol in healthy individuals and patients with COPD. Respiration 2014;88(2):101111.

13. Qi GS, Zhou ZC, Gu WC, Xi F, Wu H, Yang WL, et al. Detection of the airway obstruction stage in asthma using impulse oscillometry system. J Asthma 2013;50(1):45-51.

14. Peters U, Hernandez P, Dechman G, Ellsmere J, Maksym G. Early detection of changes in lung mechanics with oscillometry following bariatric surgery in severe obesity. Appl Physiol Nutr Metab 2016; 41(5):538-547.

15. Reisch S, Steltner H, Timmer J, Renotte C, Guttmann J. Early detection of upper airway obstructions by analysis of acoustical respiratory input impedance. Biol Cybern 1999;81(1):25-37.

16. Nilsson AM, Theander E, Hesselstrand R, Piitulainen E, Wollmer P, Mandl T. The forced oscillation technique is a sensitive method for detecting obstructive airway disease in patients with primary Sjogren's syndrome. Scand J Rheumatol 2014;43(4):324-328.

17. Shah RM, Sexauer W, Ostrum BJ, Fiel SB, Friedman AC. Highresolution $\mathrm{CT}$ in the acute exacerbation of cystic fibrosis: evaluation of acute findings, reversibility of those findings, and clinical correlation. AJR 1997;169(2):375-380.

18. Brody AS, Klein JS, Molina PL, Quan J, Bean JA, Wilmott RW. High-resolution computed tomography in young patients with cystic fibrosis: distribution of abnormalities and correlation with pulmonary function tests. J Pediatr 2004;145(1):32-38.

19. Weber K, Paolini M, Schmitz M, Fischer R, Coppenrath E, Huber R, et al. Cystic fibrosis in adults: short-term and long-term reproducibility of the Brody score for lung morphology in low-dose MDCT scans. Rofo 2014;186(1):54-60.

20. Madani A, Keyzer C, Gevenois PA. Quantitative computed tomography assessment of lung structure and function in pulmonary emphysema. Eur Respir J 2001;18(4):720-730.

21. Camilo GB, Carvalho AR, Machado DC, Mogami R, Melo PL, Lopes AJ. CT pulmonary densitovolumetry in patients with acromegaly: a comparison between active disease and controlled disease. Br J Radiol 2015;88(1054):20150315.
22. Wielpütz MO, Weinheimer O, Eichinger M, Wiebel M, Biederer J, Kauczor HU, et al. Pulmonary emphysema in cystic fibrosis detected by densitometry on chest multidetector computed tomography. PLoS One 2013;8(8):e73142.

23. Wielpütz MO, Eichinger M, Weinheimer O, Ley S, Mall MA, Wiebel $\mathrm{M}$, et al. Automatic airway analysis on multidetector computed tomography in cystic fibrosis: correlation with pulmonary function testing. J Thorac Imaging 2013;28(2):104-113.

24. Farrell PM, Rosenstein BJ, White TB, Accurso FJ, Castellani C, Cutting GR, et al. Guidelines for diagnosis of cystic fibrosis in newborns through older adults: Cystic Fibrosis Foundation consensus report. J Pediatr 2008;153(2):S4-S14.

25. Goss $\mathrm{CH}$, Burns JL. Exacerbations in cystic fibrosis. 1: Epidemiology and pathogenesis. Thorax 2007;62(4):360-367.

26. Fuchs HJ, Borowitz DS, Christiansen DH, Morris EM, Nash ML, Ramsey BW, et al. Effect of aerosolized recombinant human DNase on exacerbations of respiratory symptoms and on pulmonary function in patients with cystic fibrosis. The Pulmozyme Study Group. N Engl J Med 1994;331(10):637-642.

27. Miller MR, Hankinson J, Brusasco V, Burgos F, Casaburi R, Coates A, et al. ATS/ERS Task Force. Standardization of Spirometry. Eur Respir J 2005;26(2):319-338.

28. Pereira CAC, Sato T, Rodrigues SC. New reference values for forced spirometry in white adults in Brazil. J Bras Pneumol 2007;33(4): 397-406.

29. Neder JA, Andreoni S, Castelo-Filho A, Nery LE. Reference values for lung function tests. I. Static volumes. Braz J Med Biol Res 1999;32(6):703-717.

30. Neder JA, Andreoni S, Peres C, Nery LE. Reference values for lung function tests. III. Carbon monoxide diffusing capacity (transfer factor). Braz J Med Biol Res 1999;32(6):729-737.

31. Di Mango AM, Lopes AJ, Jansen JM, Melo PL. Changes in respiratory mechanics with increasing degrees of airway obstruction in COPD: detection by forced oscillation technique. Respir Med 2006; 100(3):399-410.

32. Cavalcanti JV, Lopes AJ, Jansen JM, Melo PL. Detection of changes in respiratory mechanics due to increasing degrees of airway obstruction in asthma by the forced oscillation technique. Respir Med 2006;100(12):2207-2219.

33. Melo PL, Werneck MM, Giannella-Neto A. New impedance spectrometer for scientific and clinical studies on the respiratory system. Rev Sci Instrum 2000;71(7):2867-2872.

34. Gattinoni L, Caironi P, Pelosi P, Goodman LR. What has computed tomography taught us about the acute respiratory distress syndrome? Am J Respir Crit Care Med 2001;164(9):1701-1711.

35. Carvalho AR, Spieth PM Pelosi P, Beda A, Lopes AJ, Neykova B, et al. Pressure support ventilation and biphasic positive airway pressure improve oxygenation by redistribution of pulmonary blood flow. Anesth Analg 2009;109(3):856-865.

36. Lopes AJ, Mogami R, Camilo GB, Machado DC, Melo PL, Carvalho AR. Relationships between the pulmonary densitometry values obtained by $\mathrm{CT}$ and the forced oscillation technique parameters in patients with silicosis. Br J Radiol 2015;88(1049):20150028.

36. Dawson B, Trapp RG. Basic and clinical biostatistics, 4th ed. New York: Lange Medical Books/McGraw-Hill; 2004:236-55, 438.

37. Helbich TH, Heinz-Peer G, Eichler I, Wunderbaldinger P, Götz M, Wojnarowski C, et al. Cystic fibrosis: CT assessment of lung involvement in children and adults. Radiology 1999;213(2):537-544.

38. Santos MK, Cruvinel DL, de Menezes MB, Teixeira SR, Vianna EO, Elias Júnior J, et al. Quantitative computed tomography analysis of the airways in patients with cystic fibrosis using automated software: correlation with spirometry in the evaluation of severity. Radiol Bras 2016;49(6):351-357. 


\section{Assessing Lung Damage in Adults With CF}

39. Martiniano SL, Sagel SD, Zemanick ET. Cystic fibrosis: a model system for precision medicine. Curr Opin Pediatr 2016;28(3):312317.

40. Mall M, Grubb BR, Harkema JR, O’Neal WK, Boucher RC. Increased airway epithelial $\mathrm{Na}+$ absorption produces cystic fibrosislike lung disease in mice. Nat Med 2004;10(5):487-493.

41. Wielpütz MO, Eichinger M, Zhou Z, Leotta K, Hirtz S, Bartling $\mathrm{SH}$, et al. In vivo monitoring of cystic fibrosis-like lung disease in mice by volumetric computed tomography. Eur Respir J 2011; 38(5):1060-70.

42. Coxson HO, Rogers RM. Quantitative computed tomography of chronic obstructive pulmonary disease. Acad Radiol 2005;12(11):1457-1463.

43. Oostveen E1, MacLeod D, Lorino H, Farré R, Hantos Z, Desager K, et al. The forced oscillation technique in clinical practice: methodology, recommendations and future developments. Eur Respir J 2003; 22(6):1026-1041
44. Ramsey KA, Ranganathan SC, Gangell CL, Turkovic L, Park J, Skoric B, et al. Impact of lung disease on respiratory impedance in young children with cystic fibrosis. Eur Respir J 2015;46(6): 1672-1669.

45. Lopes AJ, de Melo PL. Brazilian studies on pulmonary function in COPD patients: what are the gaps? Int J Chron Obstruct Pulmon Dis 2016;11:1553-1567.

46. Dressel H, Filser L, Fischer R, Marten K, Müller-Lisse U, de la Motte D, et al. Lung diffusing capacity for nitric oxide and carbon monoxide in relation to morphological changes as assessed by computed tomography in patients with cystic fibrosis. BMC Pulm Med 2009;9:30.

47. Penafortes JT, Guimarães FS, Moço VJ, Almeida VP, Menezes SL, Lopes AJ. Relationship between body balance, lung function, nutritional status and functional capacity in adults with cystic fibrosis. Braz J Phys Ther 2013;17(5):450-457. 